\title{
Incorporando el valor social en las licitaciones públicas: un modelo integral
}

\author{
José Luis Retolaza, Leire San-Jose, Maite Ruiz- \\ Roqueñi, Andrés Araujo, Ricardo Aguado, Sara \\ Urionabarrenetxea, Domingo García-Merino y Leire \\ Alcañiz González
}

\section{RESUMEN}

Existe una creciente preocupación de la sociedad sobre el valor social que se genera o destruye a través de la actividad económica; en el caso de las licitaciones públicas no sólo deberían valorarse los aspectos económicos sino también los sociales. En este trabajo se identifica la problemática vinculada a dicha valoración, se identifican el conjunto de variables implicadas en el valor de los outputs generados, y se propone un modelo que integre valores complementarios al económico. Los cuales se identificarían mediante cuatro fuentes complementarias de información sobre el valor generado: distribución del valor económico, valor social específico, inclusión del riesgo potencial, y valor emocional. Asimismo, se propone que a largo plazo la opción más eficiente consistiría en desarrollar y homogeneizar una contabilidad social para el conjunto de organizaciones.

PALABRAS CLAVE: Valor Social, Cláusulas sociales, Teoría de stakeholder, Monetización, Contabilidad social, SROI, Valor generado y distribuido, Cuarto estado financiero.

CLAVES ECONLIT: H49, M41, M48.

Cómo citar este artículo: RETOLAZA, J.L. et al. (2015): "Incorporando el valor social en las licitaciones públicas: un modelo integral", CIRIEC-España, Revista de Economía Pública, Social y Cooperativa, 85, 55-82.

Correspondencia: Autor para correspondencia: José Luis Retolaza, Universidad de Deusto. E-mail: joseluis.retolaza@deusto.es. 


\section{Incorporation de la valeur sociale dans les appels d’offres publiques : un modèle global}

RÉSUMÉ : Il existe une préoccupation croissante au sein de la société concernant la valeur sociale générée ou détruite par l'activité économique. On considère que, dans le cas des appels d'offres publiques, on devrait évaluer non seulement les aspects économiques, mais aussi les aspects sociaux. Dans cet article, nous avons identifié les problèmes liés à cette évaluation : il s'agit d'un ensemble de variables impliquées dans la valeur des outputs générés, et nous proposons un modèle qui intègre des valeurs complémentaires au modèle économique. Ces valeurs complémentaires seraient déterminées par quatre sources d'informations complémentaires sur la valeur générée : la répartition de la valeur économique, la valeur sociale spécifique, le risque potentiel et la valeur émotionnelle. De même, nous suggérons que, dans le long terme, l'option la plus efficace soit le développement et l'homogénéisation d'une comptabilité sociale pour l'ensemble des organisations.

MOTS CLÉ : Valeur sociale, clauses sociales, théorie des stakeholders, monétisation, comptabilité sociale, SROI (retour social sur investissement), valeur générée et répartie, quatrième état financier.

\section{Incorporating social value into public contracts - an integral model}

ABSTRACT: There is rising concern in society regarding the social value created or destroyed by economic activity. In the case of public contracts, not only economic but also social aspects should be taken into account. This paper identifies the problems involved in this assessment and the set of variables involved in the value of the outputs generated, and proposes a model which includes values that complement economic ones. These values are identified through four complementary sources of information on the value generated: distribution of economic value, specific social value, inclusion of the potential risk, and emotional value. It is also proposed that the most efficient option in the long term would be to develop and standardise social accounting for all organizations.

KEY WORDS: Social value, social clauses, stakeholder theory, monetarisation, social accounting, SROI, value generated and distributed, financial fourth estate. 


\section{1.- Introducción 1}

Cada vez resulta más evidente que la función de las organizaciones, incluidas las mercantiles, no se reduce a la generación de valor económico, sino que resulta consustancial a las mismas la generación de valor para el conjunto de la ciudadanía, lo que podríamos denominar como valor social, global, integral o cualquier otro término (Retolaza et al., 2015). Sin embargo, en las licitaciones de la administración pública, raramente se tiene en cuenta el potencial valor social generado por las diferentes organizaciones ofertantes.

En la actualidad parecen superadas, al menos en parte, las reticencias iniciales relativas a que las cláusulas sociales vulneraban la libre competencia (González de Olano y Navarro, 2014; Fons, 2015). A nivel nacional, la incorporación progresiva por parte de distintas administraciones de cláusulas sociales, y en especial la "Social Value Act" británica (Social Value Act, 2013; 2015), en el ámbito europeo, han venido a validar en la práctica la tesis de que las administraciones públicas podían proponer criterios sociales en las licitaciones públicas, siempre que éstas fueran coincidentes con los objetivos públicos orientados al bien común de la ciudadanía, y respeten los criterios de libre competencia.

No obstante, la repetición de hábitos en las licitaciones, así como la dificultad de establecer criterios objetivos que permitan la cuantificación del valor social, lleva a un desarrollo totalmente insuficiente de la inclusión del valor social en las licitaciones públicas (CNMC, 2015). La literatura referente es prácticamente inexistente, de ahí, el gran interés de realizar contribuciones con objeto de mejorar el modelo de valoración de las licitaciones públicas, que justifica el esfuerzo de esta investigación y de otras futuras en la misma línea.

La principal aportación de la investigación consiste en mostrar la importancia que diversas variables vinculadas a los outputs resultantes tienen en las licitaciones; entre ellos, la calidad, el riesgo, el retorno social, incluidos costes e ingresos, la innovación social, y el valor emocional (Retolaza et al. 2016). Así, se desarrolla una metodología robusta que se podría incorporar en las licitaciones públicas, permitiendo una mejor captación del valor social realmente generado y distribuido por las organizaciones, tanto sociales como mercantiles, y con una menor distorsión del mercado que el producido por las cláusulas sociales cualitativas, y en particular por los mercados restringidos o tutelados.

1.- La investigación se ha desarrollado en el marco del Proyecto Universidad-Sociedad de la UPV/EHU, denominado Valor Social de las licitaciones, desarrollado de forma conjunta (action research) entre la Asociación Gorabide y el Grupo de investigación ECRI (www.ehu.eus/ecri), compuesto por investigadores de la UPV/EHU, de la Deusto Business School. 
El trabajo tiene la siguiente estructura. En el siguiente apartado, a partir de la ejemplificación de los casos de Wal-Mart y de la Social Act, se reflexiona sobre el problema. En los dos siguientes apartados se realiza una revisión de la normativa relacionada con las licitaciones, y de la literatura científica existente sobre valoración de licitaciones; que va desde el binomio calidad-precio hasta las nuevas evidencias sobre los procesos de licitación. La siguiente sección identifica los supuestos que están en la base de los errores de valoración e ineficiencia de los procesos de licitación actuales; para a continuación realizar una propuesta basada en el cálculo coste-beneficio. En el último apartado previo a las conclusiones, se desarrolla una propuesta concreta para incorporar el valor económico integral en los criterios, y en el consiguiente cálculo, de la adjudicación; así mismo se proponen procesos de aplicación inmediata, como el del análisis del valor generado y distribuido, que permitan mejorar los procesos de licitación desde este mismo momento. Por último, el trabajo finaliza con las conclusiones, algunas limitaciones y las futuras líneas de investigación.

\section{2.- Las licitaciones públicas como oportunidad para la generación de valor social}

La contratación pública mueve un valor estimado de entre el 10-15\% del PIB mundial según la OMC -World Trade Organization- (Bajari y Lewis, 2011). Según la OCDE, en términos cuantitativos, la contratación pública en los países desarrollados supera el 15\% del Producto Interior Bruto (PIB); situándose en la Unión Europea (UE-27), en el año 2012 en torno al 19\% (2.450 miles de millones), dándose en el 2012, un incremento superior al 1\% (U.E. 2014). En el caso español, a pesar de la fuerte disminución de la misma durante la crisis actual, se sitúa en el 18,5\% del PIB; es decir, unos 194.000 millones de euros anuales (incluidas utilities), o lo que es lo mismo superaría los $4.100 €$ per cápita al año (CNMC, 2015).

Dichos contratos públicos tienen por finalidad la obtención de obras, bienes o servicios que la administración pone a disposición de la ciudadanía; sin embargo en muchas ocasiones la licitación se hace única -o prioritariamente- en función del precio (Bergman y Lundberg, 2013), sin tener en cuenta el impacto global que la relación generada por la licitación puede tener en la propia comunidad de la cual emana la institución licitadora (Kanapinskas et al., 2014). No puede obviarse que la contratación pública no es un fin en sí mismo, sino una potestad jurídica al servicio de los fines de interés general propios de la administración contratante. En este sentido es necesaria, no sólo una toma de conciencia de las administraciones públicas, que se ha empezado a dar en los últimos años, en relación con la responsabilidad social de la contratación pública; sino también, dotar a dichas entidades de herramientas que les permitan objetivar el proceso de cuantificación del valor socio-económico integral generado (o destruido) en cada proceso de licitación. 
En artículos anteriores (Ruiz-Roqueñi et al., 2007; Retolaza et al., 2008) se ha aludido al doble papel de la administración, por una parte como adquiriente de un bien o servicio concreto, y por otra como responsable del bienestar de la comunidad. Y aunque ambos papeles deberían estar entrelazados, ocurre con frecuencia, que el primero se le asigna a un departamento concreto, con unos objetivos, indicadores y presupuestos concretos, perdiendo, en demasiadas ocasiones, la perspectiva general de responsabilidad atribuible al conjunto de la administración. En estos casos, se da lo que podría considerarse como una "miopía de la contratación pública"; donde aunque se consiguiera la mejor relación precio-calidad (vamos a suponer que la miopía no afecta a la calidad) para una licitación concreta, no optimiza el valor que podría conseguir para el conjunto de la comunidad que la legítima. Nuestra hipótesis es que esto ocurre porque las administraciones en cuestión utilizan un concepto restringido de valor (visualización a corto), que sólo tiene en cuenta la relación entre inputs y outputs, de forma limitada y a corto plazo. En palabras de Freeman, estaríamos analizando el valor desde una "narrow economic view of business" (Freeman, 2006: 38) vinculada al paradigma económico neoliberal, que considera el precio como un indicador optimo del valor. Los procesos económicos, y por ende las licitaciones, generan unas externalidades que pueden ser tanto positivas como negativas, y que resulta imprescindible integrar en el análisis, si se quiere tener una perspectiva real del valor generado o destruido; a modo de ejemplificación recurriremos al caso de Wal-Mart y al de la Social Act británica.

Como señala Cascio (2006) en el análisis comparativo que hace entre Costco y Wal-Mart, es importante tener en cuenta que el modelo de mano de obra barata es costoso en muchas maneras; puede generar pobreza y problemas sociales relacionados, transfiriendo sus ahorros como costes a otras empresas 0 a los contribuyentes, que deben sufragarlos a través de programas sociales 0 de salud; tal como analiza Fishman (2006a y 2006b) en relación con los Estados de Georgia y Tennessee. En esta misma línea un trabajo del Institute for Labor and Employment de la Universidad de Berkeley (Arindrajit y Ken, 2004) estima que los contribuyentes de California financian con un total de 20,5 millones de dólares la atención médica de los empleados de Wal-Mart en ese Estado. A nivel más general, el Democratic Staff of the Committee on Education and the Workforce calculó hace ya más de una década (Miller, 2004) que el coste para los ciudadanos era de 2.103 \$ por cada trabajador, que multiplicado por 1,2 millones de trabajadores que la empresa tiene en Estados Unidos, generaría un coste social de 2.523,6² millones de dólares, derivados principalmente de ayudas a alimentación y vivienda, deducciones en el pago de impuestos, ayudas a la salud y al coste energético. Traemos a colación el caso de Wal-Mart porque es un ejemplo bien estudiado de cómo un precio bajo directo puede trasladarse a un coste alto indirecto; en este sentido, sería un claro ejemplo de miopía (pérdida de visión a larga distancia) el que la Administración realizara una compra a la citada empresa contemplando únicamente el precio, sin incorporar el conjunto de costes que realmente debe soportar.

2.- Cifra cercana a los 2,66 billones calculados, posiblemente de forma más exacta en un artículo de Bloomberg de 2013 http://www.bloombergview.com/articles/2013-12-18/always-low-wages-wal-mart-s-other-choices. 
Para Freeman (2006), el "Wal-Mart" effect enunciado por Fishman (2006b) no es sino un caso particular del "Stakeholder Effect", donde se prioriza la interacción entre la empresa y uno de los stakeholders participantes (accionistas, clientes), sin tener en cuenta el valor conjunto generado, destruido o externalizado en las relaciones con la totalidad de stakeholders.

En esta línea argumental podemos utilizar el caso de la "Social Value Act" de Gran Bretaña (Social Value Act, 2013); se trata de una ley que entró en vigor el 31 de enero de 2013 y que tiene por finalidad intentar que las personas responsables de la licitación pública piensen en cómo se pueden obtener beneficios sociales, económicos y ambientales más amplios. Previamente al inicio del proceso de adquisición, los comisionados deben pensar si los servicios que van a adquirir, o la forma en la que lo van a hacer, optimiza los beneficios posibles para su área o grupos de interés. En este sentido, la ley es una herramienta para ayudar a los comisionados a obtener más valor (output) por el dinero de la contratación (input). También anima a los responsables a interactuar con los proveedores locales y comunitarios para mejorar el diseño de los servicios y buscar soluciones innovadoras que generen un mayor valor social para la comunidad.

En relación con esta ley Frith (2014) en un artículo conceptual expone la diferencia y/o relación entre el capital ético y el capital social. Para su entender el capital social es moralmente neutro, y se refiere a las relaciones sociales, que podrían tener resultados tanto positivos como negativos (Adler y Kwon, 2002), el capital ético sin embargo indica la disposición económica de un agente para pagar por una responsabilidad moral de la empresa que supere los estándares establecido por las leyes" (Wagner-Tsukamoto, 2007: 213). Asimismo Frith (2014) concluye señalando que la Social Value Act permitirá la inclusión de aspectos sociales, incluso éticos además de los económicos en la toma de decisiones en las licitaciones públicas. En las licitaciones, muchas veces las empresas sociales compiten con entidades mercantiles, más eficientes en la fijación de precios; pero si los decisores públicos incorporan el espíritu de esta Ley y tienen en cuenta los aspectos sociales y éticos en sus decisiones, las empresas sociales pueden adquirir ventajas de un análisis de valor más global que el precio. Frith (2014) analiza esta situación en el área de la salud, en el que el valor ético y social es visible per se, y por ende, plausible su integración directa en la selección.

En el informe de evaluación realizado por el gobierno británico (Social Value Act review report, 2015), se constata que en el escaso tiempo de vigencia de la Social Value Act, se han conseguido unos importantes ahorros para la Administración Pública que cifran en 1,4 millones de libras en salud, 0,77 millones de libras en justicia, y 1,2 millones de libras en el ámbito del empleo y las pensiones. Estos retornos no eran valorados en los procesos de licitación tradicionales, y por lo tanto difícilmente podían ser tenidos en cuenta para valorar la eficiencia (relación entre inputs y outputs) de las ofertas presentadas. No obstante, el propio informe señala como carencia que en la actualidad, los procedimientos para medir el retorno social no se encuentran todavía bien definidos, lo que dificulta su utilización sistemática estandarizada en los procesos de evaluación de las licitaciones. 


\section{3.- Marco de referencia político y legislativo de las licitaciones públicas en España}

El razonamiento subyacente al actual modelo de licitación de la unión Europea es que la competencia es beneficiosa para el sistema y para el conjunto de la ciudadanía, por cuanto permite reducir los costes de obtención de un determinado producto o servicio; lo que redunda en el buen uso de los recursos públicos, o lo que debiera ser lo mismo, de los intereses de los ciudadanos. En este sentido, cabe señalar que Transparency International (2006) estima que las desviaciones al alza por prácticas relacionadas con las barreras a la concurrencia competitiva en las licitaciones públicas pueden suponer un sobrecosto de más de un $25 \%$; lo que en España podría suponer hasta un 4,6\% del PIB anual, aproximadamente 47.500 millones de euros/año (CNMC, 2015). Desde esta perspectiva pudiera parecer lógica la supresión de cualquier elemento que reduzca la libre competencia, referida especialmente al precio; como señala textualmente la Comisión Nacional de los Mercados y la Competencia, al indicar que entre sus objetivos, en relación con las licitaciones públicas, se encuentra "la supresión de sistemas de valoración insuficientemente claros o excesivamente subjetivos, dando preeminencia al precio siempre que sea posible" (CNMC, 2015: 10); o el propio Tribunal de Justicia de la Unión Europea, que en diversas sentencias ha invalidado requisitos sociales establecidos por la entidad licitadora (Fons, 2009: 2015), por entender que vulneran la libre competencia.

En paralelo a esta línea de ortodoxia neoliberal, surge progresivamente otra perspectiva que considera que "la compra y contratación públicas deben ser claras herramientas para el impulso de la RSE, enviando señales al mercado de que serán reconocidas y premiadas las empresas que brindan a la sociedad un valor adicional en materia ambiental y social" como señala textualmente el informe del Parlamento Español (BOE, 2006: 116 ); amparadas en la Directiva del 2004/18, que incorpora la idea de que la contratación pública no puede ser sólo un instrumento para adquirir unas prestaciones al mejor precio, sino que ha de servir al sector público para promover aquellas políticas o intereses generales para los que los ciudadanos hemos elegido a nuestros gobernantes (Gallardo, 2014). En esta misma línea, la Ley 30/2007, de 30 de octubre, de Contratos del Sector Público (LCSP), ofrece cierto margen para implementar criterios sociales en los pliegos de contrataciones; en especial, relacionados con la inclusión laboral de colectivos desfavorecidos (artículos 102, 134 y disposición adicional sexta).

No obstante, esta misma ley en su artículo $1^{\circ}$, señala que para la consecución del objeto de la contratación administrativa es necesario que la licitación se satisfaga mediante la adjudicación de su ejecución a la oferta económicamente más ventajosa, con respeto a cuatro principios fundamentales: 1) libertad de acceso a las licitaciones, 2) publicidad y transparencia de los procedimientos, 3) no discriminación e igualdad entre los candidatos y 4) salvaguardando los principios de la libre competencia. La libre competencia es, pues, uno de los principios que ordenan el procedimiento de selección de contratistas, buscando garantizar un trato igualitario a cualquier potencial proveedor, 
independientemente del país de referencia de la empresa oferente. Así pues, los criterios de adjudicación deben seguir manteniendo los requisitos establecidos en la Directiva 2004/18, como son: incorporarlos en el anuncio de licitación, especificar el método de cuantificación y poderse ponderar de forma objetiva. Precisamente este último punto aplicado al valor social es el objeto de nuestro trabajo.

Recientemente la Directiva 2014/24/UE, de 26 de febrero, promociona la utilización de criterios de adjudicación complementarios al económico, en lo que se conocen como contratos públicos de cuarta generación, buscando «mejor relación calidad-precio» como concepto más avanzado y global que el de la "oferta económicamente más ventajosa" que hasta ahora habíamos manejado procedente de las Directivas de 2004 (Gallardo, 2014). Se podría considerar que el nuevo «paquete» de directivas de contratación pública genera un nuevo contexto normativo con los objetivos de: 1) garantizar el uso eficiente de los recursos públicos, 2) conseguir una mayor participación de las pymes e 3) incrementar la importancia de las cláusulas de contenido social y medioambiental (González de Olano y Navarro, 2014). Con base en esta cuarta generación de Directivas Europeas, cabría poder esperar, que la contratación pública no se considere un fin en sí mismo, sino un instrumento al servicio de los objetivos públicos. En este sentido, la contratación pública debe considerarse también política pública, contribuyendo a conseguir objetivos sociales y medioambientales, de la misma manera que otras actuaciones financiadas por las administraciones con recursos públicos. "Los contratos públicos no constituyen en este sentido, simplemente un medio para abastecerse en las condiciones más ventajosas desde un punto de vista económicamente reducido o clásico. A través de ellos, los poderes públicos, entre ellos la Administración General del Estado, están interviniendo en la vida económica, social y política. Están impulsando, colaborando, en definitiva, contratando y contribuyendo al mantenimiento de empresas y agentes económicos que tienen determinados comportamientos" (Congreso de los Diputados, 2013, nº 147-1).

\section{4.- Revisión de la literatura sobre incorporación de valor social en los procesos de licitación}

De forma habitual en los contratos públicos el criterio de seleccionar consiste fundamentalmente en la utilización del precio más bajo, siempre que la oferta cumpla con los requisitos mínimos pre-establecidos en el pliego de las condiciones. Siendo el precio la principal característica a evaluar, las propuestas que podrían mejorar las características del servicio no son suficientemente valoradas; de tal forma que factores importantes como los méritos técnicos, la calidad, la experiencia, la extensión o la duración de las garantías no son factores determinantes para la selección de las licitaciones. Sin embargo, la incorporación de factores complementarios al precio para seleccionar al proveedor ofrece una más completa comparación de las propuestas (Milgrom, 2004), permitiendo aumentar el beneficio del licitador sin necesidad de reducir el valor de la entidad ofertante. 
La selección centrada en el precio, en ausencia de repetición de la contratación, no aporta ningún incentivo para que el proveedor mejore la calidad de su servicio o intente mejorar su eficiencia (Bajari y Lewis, 2011); sino que por el contrario, tiende a incentivar la eliminación de cualquier valor residual no contemplado en los pliegos de condiciones y que pueda afectar al precio, lo que limita tanto la mejora como la innovación de aquellas empresas que se focalizan en el logro de las licitaciones. En esta línea, Bajari y Lewis (2011) trabajando sobre un modelo "simulado" con datos de las autopistas de California entre el 2003 y el 2008 cuantifican las potenciales ganancias de bienestar en 1.000 millones de dólares. Asimismo, diversos estudios, entre ellos el de Bajar y Lewis (2011) insisten en la importancia de otros factores complementarios al precio, como la calidad del servicio prestado; si bien, consideran que sería necesario, no solo establecer claramente los criterios de la calidad, sino también el proceso de verificación ex -post. Pero más interesante aún es la constatación de que pequeños incentivos pueden tener efectos significativos en la mejora de los servicios contratados mediante licitación. Consecuentemente los criterios relacionados con el gasto no deberían ser un impedimento para desarrollar licitaciones públicas integrales, que tengan en cuenta solo los inputs sino también el conjunto de outputs.

Así, existen algunos trabajos que intentan avanzar en la toma de decisiones fundamentadas en otros factores diferentes al coste económico directo; por ejemplo, el trabajo desarrollado por Lorentziadis (2010) mediante la metodología de Análisis de Datos Envolventes (DEA) propone un modelo en el que los pesos de ciertos factores, preestablecidos podrían jugar un papel clave en la evaluación de las ofertas. Su propuesta se articula sobre una suma de ponderaciones lineales, seleccionando aquella oferta que maximice la división de la totalidad de puntos sobre el precio; si bien, otras opciones en el marco de la frontera de eficiencia podrían ser también válidas. El trabajo transmite la preocupación por otros aspectos complementarios al precio, con la finalidad de establecer criterios de calidad que permitan la mejora continua de aquellas empresas que concursan en las licitaciones públicas.

En esta línea Bergman y Lundberg (2013) van más allá, y concluyen que la política de decisión precio-calidad no es la más eficiente en las licitaciones públicas ya que no es transparente, está abierto a la manipulación y el precio se superpone sobre el resto de variables. La política centrada en calidad sobre precio es más adecuada según su estudio, ya que se puede asignar distintos precios según la calidad de los servicios a prestar. No obstante, defienden que en aquellas licitaciones en las que la calidad está garantizada la opción más eficiente es seleccionar aquella empresa que realiza el servicio a menor precio. No obstante, introducen un tema muy interesante, el del riesgo moral compartido por el licitador y el licitante; ya que bajo el supuesto de no existencia de control de la calidad ex-post, los proveedores pueden incurrir en mayores riesgos que pueden repercutir negativamente en el valor percibido por esta o por lo contribuyentes, o incluso en el coste del trabajo final. Lo que sugiere que sería necesario establecer controles sobre diversos aspectos de los resultados obtenidos, que puedan repercutir en el pago final, en las fianzas depositadas o en futuras licitaciones.

Otra línea de investigación de gran interés se centra en la sostenibilidad de las licitaciones, que se definirían como aquellas orientadas a satisfacer las necesidades del licitador al menor coste total 
durante la vida útil del producto o servicio prestado, con sensibilidad hacia el medio ambiente y mediante la consideración del impacto social (Kanapinskas et al., 2014). Estos autores hacen un exhaustivo análisis de las licitaciones en Lituania, concluyendo que a pesar de cumplir los criterios de transparencia, igualdad y competencia justa, no conducen a incrementos de empleo, ni a una mejora de la calidad de los servicios y productos; y que, con datos del 2013 en el que un total de 769 empresas sociales habían participado en procesos de licitación, únicamente habían tenido éxito en poco más del $1 \%$. Concluyen que las empresas sociales difícilmente pueden competir con las mercantiles cuando el criterio fundamental de adjudicación sea el precio, precisamente porque sus objetivos de valor social e inclusión laboral, no les permite optimizar el precio, aunque su eficiencia en la relación input/output pueda ser mayor. Diversos autores, entre ellos McCrudden (2004) recomiendan que se tenga en cuenta no sólo el binomio calidad-precio, sino que se incluyan también cláusulas sociales que prioricen la contratación de personas con dificultades, así como la compra social o los objetivos medioambientales. En esta línea, Gelderman et al. (2006) desarrollan un modelo para las licitaciones públicas sostenibles; identificando en Alemania, mediante la utilización de un cuestionario, diversas variables que determinan la sostenibilidad de las licitaciones: familiaridad con las políticas públicas, capacidad para percibir las posibles ineficiencias y costes en relación con dichas políticas, establecimiento de incentivos/presiones sobre las organizaciones y colaboración/resistencia de los proveedores. El desarrollo de contrataciones públicas con objetivo sostenible, requiere no sólo lograr una combinación óptima entre el costo de la vida y la calidad para cumplir con los requisitos de uso, sino tener en cuenta la generación del potencial valor social de las mismas. Siguiendo esta línea Walker y Brammer (2009) proporcionan el primer estudio sistemático e integral de la situación de las licitaciones públicas en Reino Unido. Mediante un cuestionario realizado sobre 106 funcionarios de licitaciones, segmentado en servicios generales, educación, salud y otros, se concluye que el sector público se centra más en los aspectos sociales y económicos, que en los medio ambientales. Estos mismos autores, Walker y Brammer $(2009$, p.11) defienden que "mediante la colocación de los contratos públicos de una manera estratégica, objetivos como la cohesión social, el combate del desempleo de larga duración y el logro de niveles de vida aceptables se pueden fomentar". Siguiendo el modelo de Gelderman et al. (2006) que como hemos comentado identifica los factores determinantes de las licitaciones públicas sostenibles, concluyen que la presión financiera a corto, vinculada al precio, es la principal barrera para la implementación de licitaciones públicas sostenibles. La percepción de que adquirir equipamiento, obras o servicios sostenibles implica un mayor precio, difícil de justificar financieramente, dificulta la extensión y desarrollo de las prácticas sostenibles en las licitaciones.

En un entorno más cercano se han desarrollado diversos estudios analizando la situación de las empresas sociales en relación con las licitaciones públicas; así Garcia y Bakaikoa (2014) analizan la contratación pública en el País Vasco concluyendo que entre el 1,33\% y el 3,76\% de los importes adjudicados en la contratación pública del Gobierno Vasco corresponden a la Economía Social, bastante por debajo de su cuota de participación en el PIB. 


\section{5.- La falacia de la eficiencia en la valoración de las licitaciones}

Como hemos desarrollado en los apartados anteriores, debemos afirmar que la contratación pública no puede ser sólo un instrumento para la ejecución de obras, establecimiento de servicios o prestación de suministros, sino que también presenta una gran potencialidad como instrumento de las políticas económicas y sociales, que no se puede desaprovechar. Quizás los mecanismos más inmediatos que se nos ocurren para esta optimización de la contratación pública sean los mercados restringidos y las cláusulas sociales; y en especial estas últimas por su mayor ámbito de aplicación. En sentido genérico, las cláusulas sociales se podrían considerar como estipulaciones que obligan a los adjudicatarios a dar cumplimiento, junto con el objeto propio del contrato, a ciertos objetivos de política social que se estiman de interés general. Consideramos con Fons (2009) que dichas cláusulas, en sentido estricto, harían únicamente referencia a aquellos casos en los que el objeto del contrato incorpora la promoción de valores sociales, como un añadido a las obligaciones propias del contrato. En el sentido constituirían una estipulación complementaria al cumplimiento de la obligación contractual principal, y autónoma a la misma, por cuanto que, con carácter general, dicha cláusula nada tiene que ver con las especificaciones técnicas exigidas para la ejecución del contrato. Por el contrario, no procede considerar como cláusulas sociales las estipulaciones que tienen por objeto asegurar que el contrato se realiza tomando criterios de accesibilidad universal y tutela del medio ambiente, por cuanto que los referidos criterios forman parte intrínseca del propio objeto del contrato.

Aunque creemos que las cláusulas sociales pueden y deben tener un papel cada vez más importante en las licitaciones públicas, nuestro trabajo no se centra en las mismas, sino en un problema subyacente al propio proceso de licitación, que está lastrando su optimización social y perjudicando desaprovechando el potencial social y económico de las PYMES en general y del Tercer Sector en particular: el cálculo erróneo de la relación entre costes y retornos, que ya hemos visualizado en el segundo apartado de este trabajo, mediante las externalidades negativas generadas por Wal-Mart y el impacto positivo de la Value Act Británica.

Sería una falacia considerar que la Unión Europea no se preocupa de la eficiencia, de hecho, publica anualmente informes sobre este particular (UE, Public procurement indicators), y la CNMC (2014) considera que al menos son dos objetivos fundamentales de la normativa sobre aprovisionamiento público son la eficiente utilización de los mismos y la salvaguarda de la libre competencia; sin embargo, los parámetros analizados a tal efecto, sorprenden por su irrelevancia: rapidez - medida en días- y coste de los proceso de contratación. Indudablemente parece interesante cualquier reflexión que permita la reducción de los costes del proceso, que en pequeñas licitaciones $(<125.000 €)$ se estima que pueden alcanzar el 29\% de la licitación (U.E., 2015: 20-21); no obstante, parece que estos costes no pueden ser la clave del análisis de eficiencia. Posiblemente esta superficialidad en los aná- 
lisis de eficiencia se deba al supuesto de considerar que el único factor que puede generar valor es la reducción del precio, como parece sugerir este texto de la CNMC (2014: 9) haciendo referencia a las posibles mejoras en los sistemas de licitación: "la supresión de sistemas de valoración insuficientemente claros o excesivamente subjetivos, dando preeminencia al precio siempre que sea posible". Resulta cuestionable la supuesta correlación negativa entre discrecionalidad y eficiencia (Migué et al., 1974; Stultz, 1990; Lang et al., 1995; Wangrow et al., 2015); pero resulta inaceptable el supuesto de, que en general, un menor precio redunde en una mayor eficiencia; ya que para que esto ocurra es necesario que el resto de variables implicadas en la ecuación se mantengan fijas (ceteris paribus), lo cual es imposible que suceda en contrataciones mínimamente complejas.

El planteamiento del análisis que proponemos se fundamenta en el análisis coste-beneficio, ya que la eficiencia, entendida como la optimización entre los inputs y los outputs, debe ser uno de los ámbitos de evaluación de cualquier proyecto de intervención AECA (2002). El análisis coste-beneficio, también denominado ACB, es una metodología ampliamente utilizada en el ámbito de las actuaciones públicas (Aparicio, 2013); su objetivo es cuantificar lo máximo posible los posibles inputs (recursos) y outputs (resultados) obtenidos en un determinado proyecto. Dicha metodología de análisis no es ajena a la U.E., muy al contrario, el artículo 40, letra e), del Reglamento (CE) n 1083/2006 dispone que cuando se solicite a la Comisión apoyo financiero para grandes proyectos en el marco de los Fondos Estructurales y el Fondo de Cohesión debe aportarse información sobre el análisis costes-beneficios. Podemos, por tanto, considerarla como una metodología aceptada y asentada en la U.E; sobre la que incluso esta ha publicado guías de utilización (U.E. 08/2006).

El ACB es una herramienta esencial para evaluar los beneficios económicos de los proyectos de interés público (U.E. 08/2006:4). El objetivo consiste en identificar y monetizar tanto la totalidad de los recursos utilizados, como todos los efectos posibles resultantes: financieros, económicos, sociales, medioambientales, etc. A continuación se agregan los resultados (beneficios netos) y se extraen conclusiones sobre el valor generado por dicho proyecto. A fin de calcular el valor real resultante es necesario corregir las externalidades negativas (influencia negativa sobre diversos stakeholder que no son compensados); y dado que no van a tener una compensación monetaria real no se van a visibilizar a través del análisis financiero, por lo que será necesario hacer una estimación general de las mismas y dotarlas de un valor monetario. Así mismo, la propia Unión Europea (Uyarra y Flanagan, 2010) considera que el análisis debe definirse en función de la sociedad en la que el proyecto tiene un impacto relevante; adecuándose a la misma el ámbito geográfico de los previsibles costes y beneficios: municipal, regional, nacional o comunitario. A partir de este análisis se desarrollan tres indicadores complementarios: el VANE (valor actual neto económico) que debe ser superior a cero, punto de equilibrio; el TRE (Tasa de rendimiento económico) que debe ser superior a la tasa de descuento social; y el tercero Relación B/C (beneficio-coste) que debe ser superior a uno. El VANE es más fiable (Hinojoza y Falcon, 2005), por lo que podría utilizarse como el principal indicador de referencia para la estimación de proyectos; lo que llevado a las licitaciones públicas posibilitaría su utilización como indicador principal se selección de un proyecto. Entonces, cabe preguntarse ¿Por qué se utiliza el precio como principal indicador de referencia en lugar de usar el VANE? 
La única razón que justifica este planteamiento es la suposición de que los outputs obtenidos permanecen estables entre los diferentes oferentes, o que la variación en el valor de los mismos, es irrelevante (o poco relevante) en relación con el precio, y consecuentemente a los posibles outputs alternativos que se pueden generar con dicho ahorro. Evidentemente en circunstancias de un valor similar de los outputs resultantes, habida cuenta de que la eficiencia se definiría como un ratio entre los outputs resultantes y los inputs utilizados, cualquier reducción en el precio significaría un incremento de la eficiencia. Sin embargo, podemos encontrar, al menos, seis dimensiones significativas de variabilidad en el valor de los outputs resultantes que generalmente son poco o nada tenidos en cuenta en la valoración de las licitaciones públicas: 1) Calidad, 2) Retorno económico territorial, 3) Ahorro para la Administración, 4) Innovación social, 5) Valor emocional, 6) Riesgos.

La calidad es el output que más en cuenta se ha tenido de los procesos de licitación, parecería que no tiene sentido el aceptar calidades inferiores a las necesarias, $u$ ofertas que no resulten sostenibles en el tiempo; sin embargo, son multitud las licitaciones que han saltado a los medios de comunicación en los últimos años por ofrecer una calidad insuficiente, por resultar insostenibles, o por crear todo tipo de conflictos con trabajadores y usuarios.

Por su parte, el retorno económico territorial, en el ámbito de la entidad licitante, es un tema que nunca se realiza, quizás por pensar que es contraria a la libre competencia. Sin embargo, en un análisis económico de los inputs y outputs generados por un proceso de licitación parecería imprescindible calcular el retorno que las diferentes ofertas tienen sobre el ámbito territorial gestionado por el licitante, ya que es una parte inseparable de la propia licitación. Su exclusión del análisis económico supone una simplificación del análisis coste-beneficio inconsistente con dicha metodología y con las orientaciones de la propia U.E. en relación con su uso (U.E. 08/2006).

El ahorro para la administración es la otra cara del retorno económico, por cuanto que dependiendo la forma de ejecución de la licitación, esta puede mermar en mayor o menor medida los costes que la propia administración soporta a través de otros programas de carácter social o medio ambiental. En este sentido, creemos que en muchas ocasiones no es necesaria la incorporación de cláusulas sociales específicas, sino que bastaría con calcular realmente el ahorro económico de las ofertas presentadas. Tanto esta variable como la anterior pueden ser abordadas a través de la perspectiva del Social Cost Benefit Analysis que incorpora el impacto social generado para cada uno de los grupos de interés implicados (Perman, 2003; Retolaza y San-Jose, 2011).

Podemos entender, en este caso, por innovación social la mejora cualitativa en la oferta presentada al concurso. En la actualidad esta variable tiene una ponderación insignificante en la gran mayoría de las licitaciones; basado en la creencia de que los funcionarios responsables son capaces de establecer el óptimo esperable. Sin embargo, como han demostrado diversos estudios (entre otros; Edler y Georghiou, 2007; y Hommen y Rolfstam, 2009), esto, no sólo hace que se ignore la innovación social, sino que actúa como incentivo perverso de desincentivación, impulsando a que el licitador se centre exclusivamente en la mejora del precio. Sin embargo, la innovación social es un elemento clave 
en la mejora de la calidad de vida; y que es muy difícil que los responsables la puedan incluir en el pliego como un requisito estándar, ya que para ser así, debería tratase de una innovación ya consolidada. Un mecanismo plausible sería dejar un amplio margen de valoración al análisis coste-beneficio integral, donde se ponderara el valor social atribuido a dicha innovación entre el incremento de coste.

En relación con el valor emocional, este se suele obviar, por considerarlo como algo subjetivo, propio de cada persona, sin tener en cuenta que cualquier tipo de valor es en realidad un valor reconocido intersubjetivamente. En este sentido, el enfoque moral de la eficiencia, denominado Kaldor-Hicks Moral [KHM] o Kaldor-Hicks-Zerbe [KHZ], que propone Zerbe (2001), supone una importante mejora sobre los criterios de eficiencia clásicos: Pareto, kaldor-Hicks, y kaldor-Hicks Scitovsky, al incorporar el valor moral o emocional como un output del análisis. Entre sus ventajas complementarias (Zerbe y Bellas, 2006: 14-15) se encuentra "la inclusión del valor para los non-stakeholders, inexistente en otros modelos, incluyendo los aspectos relativos a la distribución y a la sostenibilidad en el largo plazo".

Por último, tal y como señalan las recomendaciones de la propia U.E., sería necesario ponderar el riesgo presente en cada oferta, más allá de una bajada temeraria. Resulta obvio que existe un riesgo generado por la capacidad de la entidad ofertante, que va a depender de diversos factores como la experiencia, la complejidad de la solución ofertada, el precio, los recursos y capacidades disponibles por la entidad, su cultura, etc. Frente a la solución actual de considerar que el riesgo no debe valorarse en las licitaciones, sino solucionarse a posteriori; lo que genera situaciones de auténtica ineficiencia, con servicios de mala calidad, retraso en las ejecuciones o incrementos posteriores de precios; consideramos que el riesgo presentado por cada propuesta debe ponderarse y monetizarse como un input $u$ output negativo (existen las dos posibilidades según el tipo de análisis) que reste valor al resultado agregado.

A continuación (Figura 1) presentamos un modelo que incorpora las diversas variables propuestas, en el marco del análisis ACB: calidad, externalización de costes, riesgo, innovación social, retorno socio-económico y valor emocional. 


\section{Figura 1. Modelo Integral de análisis económico (ACB) para una licitación}

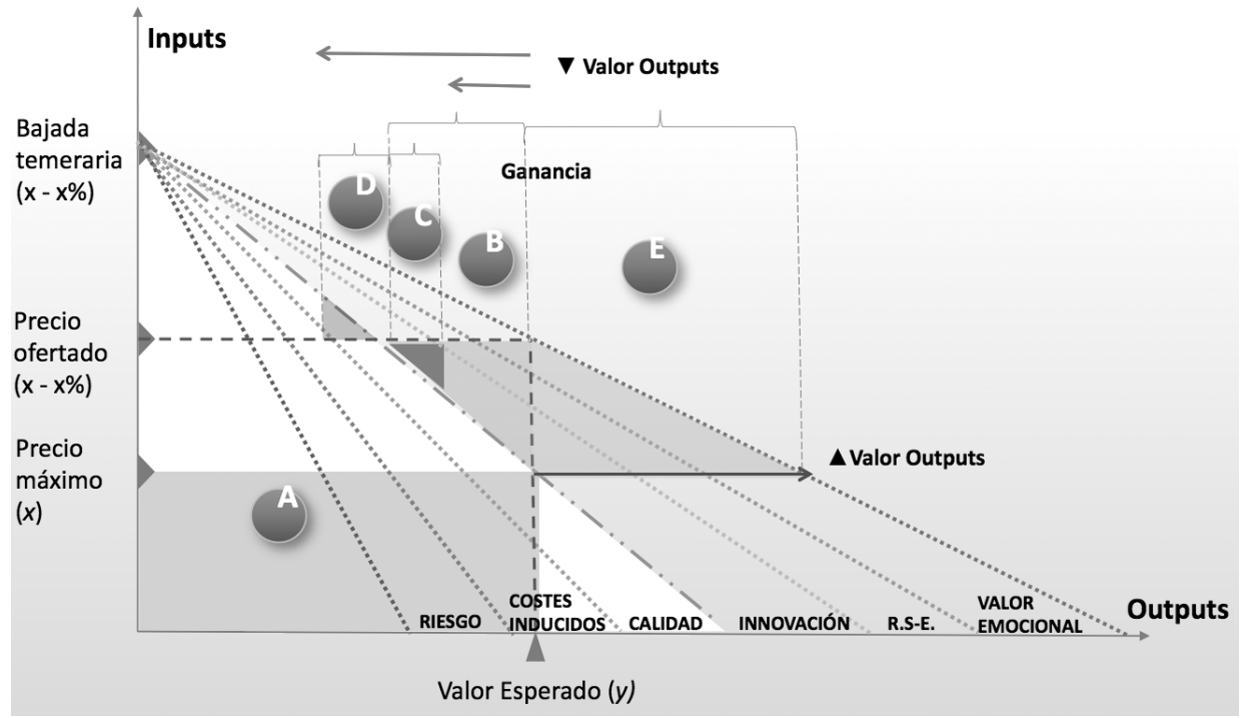

FUENTE: Elaboración propia.

La figura anterior visualiza las posibles relaciones de eficiencia entre los inputs y los output identificados en los párrafos anteriores. Entre los primeros (inputs) sólo hemos tenido en cuenta el precio, aunque se podrían considerar otros como los costes del proceso. En relación con los resultados (outputs), hemos considerado un resultado estándar [1], que refleja el definido en el pliego de condiciones de la licitación; y tres variables de empeoramiento y mejora respectivamente. Las de carácter negativo serían: la merma en la calidad [2], los posibles sobrecostes inducidos [3], y los riesgos de ineficacia en la ejecución [4]; las positivas, serían el plus de valor generado por la innovación social [5], el retorno socio-económico [6] al ámbito de responsabilidad de la entidad licitante, y el valor emocional generado [7]. De forma simplificada hemos considerado la existencia de una relación lineal entre el precio $(x)$ y el resultado esperado $(y)$ de la forma $y=m x+b$. Aunque dicha relación podría ser logarítmica, exponencial o de cualquier otro tipo, la forma concreta excede el carácter ejemplificador de la figura. En la figura esta relación lineal se representa gráficamente mediante la línea 1. En la mayoría de los procesos de licitación se considera que el resultado es estándar, dándose escasa puntuación a las posibles mejoras propuestas; en este caso, si los outputs se consideran fijos, en lugar de una variable con múltiples valores potenciales, es evidente que cualquier disminución en los costes (precios), supondrá un incremento de la eficiencia. Estaríamos situados en una relación estándar, donde a un determinado resultado $(\mathrm{y})$ se le hace corresponder un determinado precio de referencia 
$(\mathrm{x}): \mathrm{x} \equiv \mathrm{y}$; por lo que cualquier reducción de $\mathrm{x}$, manteniendo y constante, dará como resultado un incremento de la eficiencia, entendida esta como un ratio $y / x$. Gráficamente se podría visualizar como el incremento del área de $\mathrm{A}$, cuando el precio se reduce $(\mathrm{x}-\mathrm{x} \%)$.

Sin embargo, en nuestra figura hemos considerado que los outputs no son fijos, ya que el valor de los mismos se puede desplazar por el eje de abscisas ${ }^{3}$, tanto en sentido positivo en relación con el valor esperado (innovación, retorno y valor emocional), como en sentido negativo (calidad, costes y riesgos). Así, para un mismo precio (x), se podría ofertar una disminución de la calidad [2]; un incremento de los costes futuros [3], (por ejemplo mediante despidos o reducción de mantenimiento); 0 un incremento del riesgo en la ejecución [4]. Adicionalmente, se pueden ofertar mejoras complementarias [5], que deberían ser la base de la innovación social, y sin embargo son escasamente valoradas por la administración; un mayor o menor retorno socio-económico [6] para la propia administración o sus administrados; $y$ un valor emocional diferencial agregado [7] para el conjunto de los stakeholders implicados en el proyecto. Esto hace que se generen otras relaciones de valor, que en nuestro modelo hemos considerado mediante las diferentes líneas divergentes. Teniendo en cuenta que los outputs, o el valor de los mismos, pueden variar; la relación que se establece entre $\mathrm{x}$ e y puede fluctuar en diferentes direcciones, y sólo sería correcto considerar una correlación entre disminución de precio y eficiencia, en aquellos casos para los que el valor de los outputs se mantuviera constante, lo que quedaría reflejado en el valor $B$ del gráfico. Pero, habida cuenta de que en general la administración no valora el resto de las variables, la eficiencia real se convierte en una incógnita. Ya que si dicha reducción de precio llevara aparejada una disminución de valor de alguno de los tipos señalados, podríamos estar en una situación $C$, o incluso $D$ de la figura, donde la eficiencia resulta menor que en la de la propuesta estándar, a pesar de haber realizado una reducción del precio de la licitación. Por otra parte, sería posible que con un precio ostensiblemente superior, como el máximo de la licitación, fuera posible una mejor relación de eficiencia, como se puede apreciar comparando las áreas de $B$ y $E$ en el gráfico. Parecería que esta última situación puede reflejar la que se da frecuentemente en el ámbito social cuando se compara las ofertas de las entidades sociales en relación con las de las empresas mercantiles orientadas a beneficio.

A fin de poder comprender mejor los resultados de eficiencia hemos realizado la siguiente tabla con algunos supuestos tipo, de una parte hemos considerado tres opciones de precio: máximo, descuento del $10 \%$, y descuento del $20 \%$ que en general se corresponde con el límite de la bajada temeraria 4 . Por parte de los outputs hemos considerado de forma muy conservadora un $10 \%$ de incremento o decremento para cada uno de ellos, aunque trabajos previos (Retolaza et al, 2014a; Retolaza et al.,

3.- En realidad cada una de estas variables tendría un valor que puede ser superior o inferior al valor esperado; pero dado que la dirección esperada de la variación, en el planteamiento actual de las licitaciones, sería fundamentalmente negativo y positivo, respectivamente; hemos simplificado la figura teniendo en cuenta esta única posibilidad.

4.- Evidentemente, tanto las variables input como outputs son continúas, y se han tomado sólo algunos de los valores posibles, a fin de visualizar como la relación input/output se modifica tanto por el decremento del precio, como por el incremento o decremento de las variables de salida. Los supuestos se han hecho en deciles, por la facilidad de comprensión frente a otro tipo de escalas. 
2015a; Retolaza et al., 2015b; Guasch, 2015) señalan retornos cercanos o superiores al 100\% respecto al precio, tanto en relación con el valor social como emocional.

\section{Tabla 1. Simulación de los Resultados a partir del modelo de valoración de licitaciones públicas propuesto}

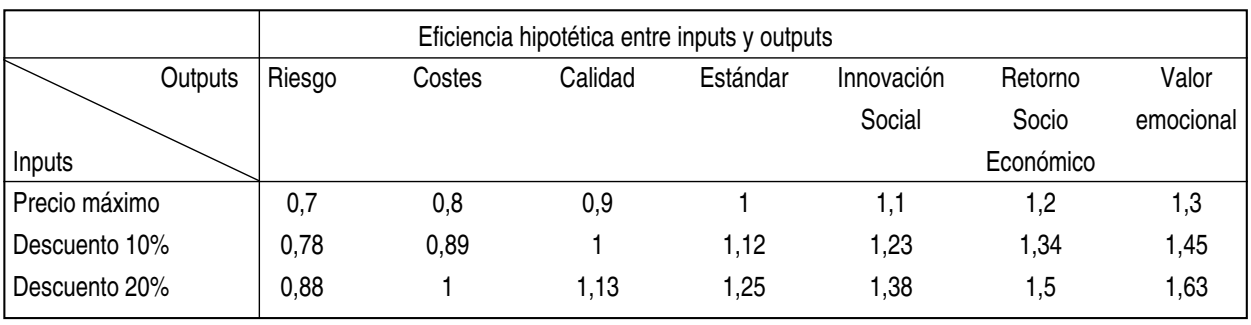

FUENTE: Elaboración propia.

Como puede apreciarse, a pesar de lo conservador de los datos utilizados, varias eficiencias del precio máximo $[1,1 ; 1,2 ; 1,3]$ superan a las del precio mínimo $[0,88]$. Por otra parte, hay que tener en cuenta que posiblemente el valor monetario del ahorro y el del valor social generado no sería siquiera el mismo. Así, mientras que el valor aportado mediante la innovación social puede traducirse en la mejora de los estándares futuros para el conjunto de los ciudadanos, el retorno socioeconómico afecta de forma positiva en el momento presente, y el valor emocional produce una sociedad más feliz; el ahorro de coste de la licitación no se suele traducir en un coste de oportunidad, ya que normalmente no se reutiliza. Por lo que podría pensarse, desde una perspectiva marginalista, que el precio máximo representa el óptimo; por cuanto que no se obtiene ninguna ganancia neta mediante el ahorro de costes de licitación, salvo la reducción del endeudamiento.

A pesar de que incluir las seis variables propuestas en la valoración de las licitaciones, permitiría que el análisis de las propuestas reflejara mucho mejor el valor realmente generado, y por tanto la eficiencia real (AECA, 2000) de los procesos de compra pública; debemos admitir que no todos los impactos socio-económicos pueden siempre cuantificarse y valorarse en términos monetarios. Por eso, además de una estimación de los indicadores de rendimiento, deben tenerse en cuenta los costes y los beneficios no monetizados, sobre todo en relación con las siguientes cuestiones: impacto (neto) en el empleo, protección del medio ambiente, igualdad social e igualdad de oportunidades. Lo cual, sin duda justifica la inclusión de cláusulas sociales complementarias. 


\section{6.- Propuesta para una valoración económica integral de las licitaciones públicas}

Hasta aquí podemos concluir que la valoración económica realizada generalmente en las licitaciones es incompleta y no refleja el valor real obtenido en las mismas, por lo cual la supuesta eficiencia del gasto público resulta inconsistente. Sin embargo, esta crítica teórica resulta baldía si junto a la misma no se proponen metodologías que permitan una mejor cuantificación de la relación inputs / outputs resultantes de un proceso de licitación. Como señalan claramente las Directivas del 2004 y 2014 (U.E.), resalta la CNMC (2014), e incluso aparece en la revisión de la Social Act (2015), es necesario establecer criterios objetivos que permitan una valoración intersubjetiva consensuada y coherente.

En relación con los inputs, habida cuenta de la centralidad del precio, no sería necesario ningún instrumento de transformación, ya que se podría tomar directamente de la oferta; en todo caso cabría establecer una tasa de descuento social como propone la U.E. (2006) en función de la utilidad alternativa que se le vaya a dar a los fondos ahorrados. En relación con los outputs la situación es más compleja y se podría proceder desde dos perspectivas, la primera sería cualitativa, considerando cada una de las variables como un output resultante. Independientemente de que las variables se cuantificaran en euros, en unidades de valor o de forma mixta, se consideraría que las unidades no serían intercambiables, así una unidad de calidad no se correspondería con una unidad de valor emocional. Incluso aunque todas las variables se pudieran cuantificar en euros, no se considerarían como un agregado; por lo que el óptimo no sería un sumatorio de los valores parciales, sino un combinado equilibrado del conjunto de variables. En esta línea se están utilizando (Falagario et al., 2012) metodologías basadas en la frontera de posibilidades de utilidad (frontera de eficiencia), y más concretamente el DEA (Data Envelopment Analysis-Análisis Envolvente de Datos); sin embargo, su complejidad matemática que hace que opere como auténtica "caja negra", impide una comprensión intuitiva del resultado obtenido, no siendo quizás el mejor instrumento para que políticos y ciudadanos podamos apreciar la validez de la selección realizada.

Otra perspectiva, bastante más consolidada, consistiría en conceptualizar el conjunto de los outputs como un agregado, que puede recibir la denominación de valor social, socio-económico, integral, global... Se trataría de traducir los diferentes outputs a unidades monetarias de similar significado. En esta línea existe un importante trabajo consolidado (Emerson et al., 2000; Clak et al., 2004; Olsen y Nicholls, 2005; Olsen y Galimidi, 2008; Tuan, 2008; Mulgan, 2010; Wood, 2010; Retolaza y San-Jose, 2011, Retolaza et al., 2012, 2014a y 2016) con dos planteamientos complementarios, en uno, el centro de atención sería la propia licitación, considerada como una inversión, donde se trataría de calcular el retorno integral de la misma a la Sociedad que la soporta; siendo la metodología más consolidara en este ámbito el análisis SROI. De otra parte, para poder calcular el retorno de la licitación resulta necesario tener de forma previa datos contrastados del valor social generado por las entidades licitantes, para lo que sería recomendable que estas llevaran una con- 
tabilidad social de su proceso de explotación; pudiendo utilizarse la metodología SPOLY (Social Polyhedral Model), soportada en la teoría de stakeholder (Freeman, 1984; Retolaza y San-Jose, 2011; Retolaza et al., 2014b). Dicha metodología permite cuantificar el valor social generado por cualquier organización, ya sea social o mercantil, a través de la consolidación de tres categorías o ecosistemas de valor: 1) impacto social de la actividad económica; 2) retorno a la administración; 3) valor social específico generado a los diversos grupos de interés. Un ejemplo del resultado del SPOLY puede verse en la siguiente Figura (Figura 2).

\section{Figura 2. Análisis SPOLY de Formació y Treball (año 2013)}

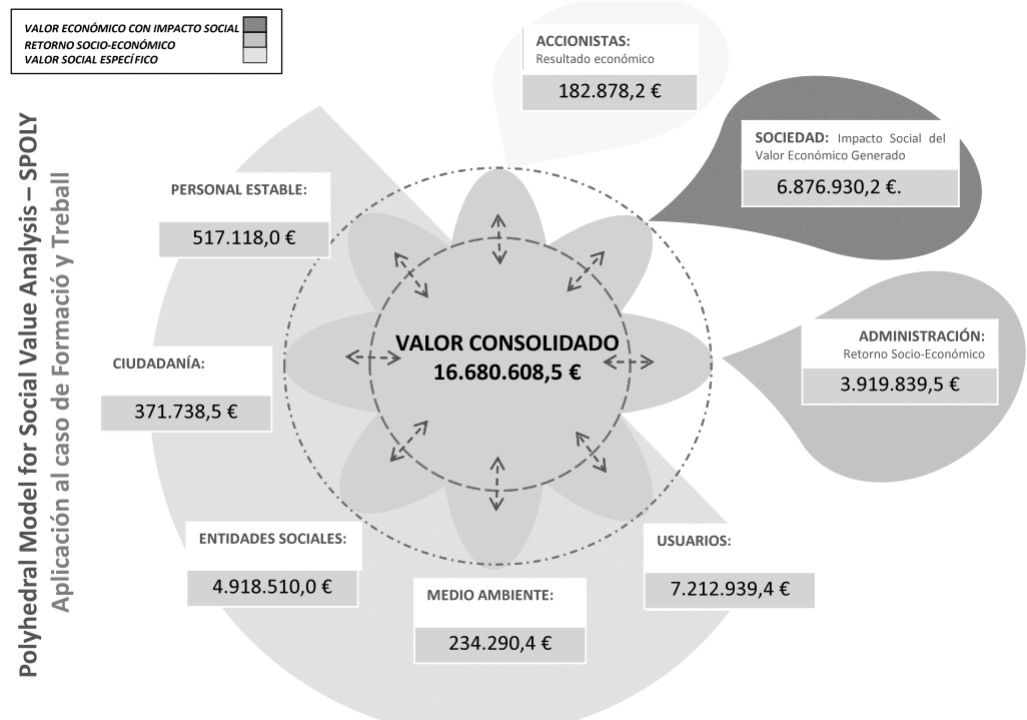

FUENTE: Tomada de Retolaza et al., 2015b.

En la figura anterior se puede visualizar el valor social (económico con impacto social + social específico) generado por $\mathrm{FiT}^{5}$ para los diferentes stakeholders, así como el valor conjunto consolidado. Teniendo en cuenta que el presupuesto de la entidad para el 2013 fue de $3.407 .029 €$, significaría que el impacto social por euro facturado fue de 4,9 euros. Aunque este cálculo no se puede generalizar para calcular el retorno de una licitación futura, lo cierto es que con estos datos más la propuesta concreta realizada, la administración en cuestión puede calcular, no sólo el retorno para la propia administración, sino también la generación de valor social para el conjunto de los administrados.

5.- La Fundación Formació i Treball (FIT) fundada el 1992 y promovida por Cáritas Diocesana de Barcelona, tiene como principal objetivo la formación e inserción laboral de personas con especiales dificultades personales y sociolaborales; gestiona el abastecimiento de ropa, muebles y equipamiento del hogar para familias con pocos recursos derivadas de diferentes servicios sociales (Cáritas, ayuntamientos, parroquias, otras entidades). Para lograr su misión, la Fundación Formació $i$ Treball participa en las siguientes sociedades mercantiles vinculadas: Formació i Treball Empresa de Inserción, S.L.U., Roba Amiga Empresa de Inserción, S.L., e Instituto de Formación para la Inserción Laboral, S.L.U. (más información: http://www.formacioitreball.org). 
Para que la administración licitadora pudiera hacer un buen análisis del retorno, sería interesante conocer el valor social generado por cada una de las organizaciones licitante en relación con su facturación, de forma que con las correcciones resultantes del proyecto particular limitado, se pudiera realizar una extrapolación del valor social que se generaría. En la medida en que las organizaciones puedan facilitar datos contrastados de su generación de valor, facilitarían enormemente el análisis del retorno por parte de la administración. Sin embargo, hasta que la contabilidad social no se generalice, es de suponer que la administración no va a poder acceder a estos datos de forma sistemática y eficiente.

Una forma intermedia de valorar el impacto social de las licitaciones sería utilizar el análisis del valor añadido (AECA, 2002) o del valor generado y distribuido (GRI4); nosotros preferimos este segundo análisis (Retolaza et al., 2015a) por incluir el gasto en proveedores que es sin duda uno de los principales circuitos de que los fondos reviertan en la propia comunidad a través de la compra a proveedores locales. Estos análisis de valor generado y distribuido, que las grandes empresas están empezando a introducir mediante el GRI (G4. EC1) son muy similares a lo que, principalmente en Suramérica, se denomina como cuarto estado financiero (Pereda y Zicari, 2012; González et al., 2013). La ventaja de este tipo de análisis consiste en que se pueden realizar a partir de las cuentas registradas, sin necesidad de solicitar a las organizaciones información, salvo datos relativos a los gastos a realizar en el marco de la propia licitación.

En la siguiente tabla (Tabla 2) se recogen los componentes propuestos por el GRI 4 (2013) para integrar la información relativa al valor creado y distribuido por una organización.

\section{Tabla 2. Componentes propuestos por el GRI}

\begin{tabular}{|l|l|}
\hline Componente & \multicolumn{1}{|l|}{ Comentario } \\
\hline Valor económico directo creado (VEC) \\
\hline a) Ingresos & Ventas netas más ingresos procedentes de inversiones financieras y venta de activos \\
\hline Valor económico distribuido (VED) \\
\hline b) Costes operativos & Pagos a proveedores, royalties y pagos de facilitación u obsequios dinerarios \\
\hline $\begin{array}{l}\text { c) Salarios y beneficios sociales } \\
\text { para los empleados }\end{array}$ & $\begin{array}{l}\text { Pagos totales realizados a los empleados y contribuciones sociales. No incluye } \\
\text { compromisos de pago futuros }\end{array}$ \\
\hline $\begin{array}{l}\text { e) Pagos a gobiernos (por país, } \\
\text { ver nota a continuación }\end{array}$ & Tasas e impuestos brutos \\
\hline f) Inversiones en la comunidad & $\begin{array}{l}\text { Aportaciones voluntarias e inversión de fondos en la comunidad en el sentido amplio } \\
\text { de la palabra (incluye donaciones) }\end{array}$ \\
\hline Valor económico retenido (VER) & Reservas, amortizaciones y depreciaciones, etc. \\
\hline $\begin{array}{l}\text { (calculado como Valor económico } \\
\text { generado menos Valor económico } \\
\text { distribuido) }\end{array}$ & \\
\hline
\end{tabular}

FUENTE: GRI 4 (2013). 
En la siguiente figura (Figura 3) se puede ver un ejemplo de la variabilidad de las organizaciones en relación con la distribución del valor entre sus diferentes stakeholders, y apreciar de forma intuitiva las diferencias que conlleva en el retorno para la comunidad en la que operan.

\section{Figura 3. Valor distribuido por las entidades Laboral Kutxa y BBVA 2014}

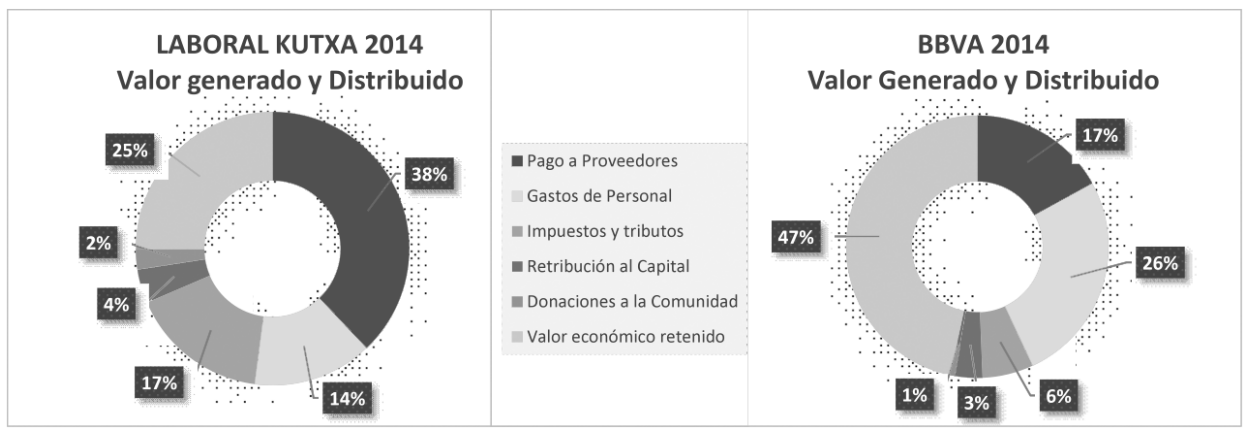

FUENTE: Elaboración propia a partir de Laboral kutxa (2014) Memoria de Responsabilidad Social Empresarial y BBVA (2012) Información de Responsabilidad Corporativa.

El valor económico generado y distribuido se correspondería en gran medida con el valor económico con impacto social del SPOLY (Retolaza et al., 2015c), por lo que podría utilizarse para calcular la reversión del pago económico en las licitaciones. Adicionalmente, se puede animar a las organizaciones, especialmente a las entidades sociales para que calculen el valor social específico generado, a fin de poder incorporarlo también en el análisis coste-beneficio del proceso de licitación. A falta de un mayor número de análisis empíricos, entendemos que en este ámbito las entidades sociales posiblemente generen un valor significativamente superior a las mercantiles, por lo que podrían estar más interesadas en su medición como propuesta de valor añadido. El sistema actual propuesto por GEAccounting 6 donde la propia entidad, de forma independiente o con apoyo, realiza la valoración, que es verificada en su proceso metodológico por un pool de Universidades; nos parece un mecanismo suficientemente objetivo para su posible inclusión en la valoración de una licitación, siempre que se haya hecho referencia a este hecho en la redacción de los pliegos de condiciones.

Por su parte, el valor emocional es un tema bastante trabajado, sí no en el área financiera, si en la de marketing, donde se han desarrollado múltiples escalas de medida (Sweeney y Soutar, 2001; Smith y Colgate, 2007; Zellwegwr y Astrahan, 2008) en relación con el valor percibido por los clientes;

6.- GEAccounting es una Agrupación (AIE) creada por las Fundaciones Lantegi Batuak y Monte Madrid, la Asociación Aurkilan, y la cooperativa Tutoring One, en la que participan varias universidades (UPV/EHU, Deusto Business School, Pompau Fabra -ESCl-, y la Universidad de Mondragón), así como las diversas entidades que prescriben o utilizan el SPOLY (más información en www.geaccounting.org). 
lo mismo podemos decir en el ámbito de la calidad o los trabajadores (Lewis y Gabrielsen, 1998; Goetsch y Davis, 2014). Aunque en relación con otros stakeholders es una práctica aún poco desarrollada, constatamos que existen los instrumentos para poder avanzar en la valoración y cuantificación del valor emocional (Zerbe, 2004), al menos en forma de índice que pudiera funcionar como factor corrector del valor previamente calculado (Guasch, 2015). En esta línea, se puede hipotetizar sobre la posibilidad de establecer un sistema de valoración similar al de la calidad, realizado por los diferentes grupos de interés implicados en el proyecto; donde la empresa adjudicataria se comprometería a mantener unos determinados niveles de satisfacción, contra penalizaciones económicas en caso de incumplimiento. Estas penalizaciones (incentivos negativos), que actuarían como motivadores, serían coherentes con la propuesta de Walker y Brammer (2009) y, en caso de incumplimiento, servirian para restablecer la eficiencia distorsionada tras la reducción en un output comprometido (valor emocional). Así, una disminución de los outputs generados, valor emocional, tendría como contrapartida la disminución en los pagos percibidos. El grado de satisfacción como criterio de evaluación es algo que se está utilizando de forma normalizada en las principales universidades del mundo, de forma bastante exitosa.

\section{7.- Conclusiones}

Que las licitaciones públicas debieran contribuir al bien de la ciudadanía, no sólo a través del objeto del contrato, sino en el conjunto de la actividad económica vinculada al mismo, es más bien una premisa que una conclusión. A partir de la misma podemos constatar que los criterios que actualmente se están utilizando para medir el retorno de las licitaciones, y por lo tanto la eficiencia del gasto público, son incompletos. De forma miope, se están analizando únicamente dos variables, quizás tres, si incluimos la calidad; cuando en realidad debieran valorarse un mínimo de siete variables, ocho si incluimos los costes del proceso.

El mayor problema reside en considerar que los outputs generados son fijos, con lo que se desincentiva, tanto la innovación social, como la generación de valor complementario para el conjunto de los stakeholders. Así mismo, se dejan de valorar los riesgos vinculados a las ofertas, que como luego se constata revierten ampliamente en la calidad y coste de las mismas. A fin de poder calcular el valor real que puede generar una determinada oferta en el ámbito de una licitación pública se debería recurrir a un análisis coste-beneficio, donde se incluyan la totalidad de las variables implicadas en la generación o destrucción de valor, optando por la propuesta que genere el mayor VANE, como reflejo de la eficiencia generada para el conjunto de la ciudadanía vinculada a la entidad licitante. 
En este sentido, las directrices de la U.E. resultan contradictorias, por un lado, tanto la nueva legislación, como las recomendaciones sobre la metodología coste-beneficio a aplicar parecen caminar en la dirección correcta, por contra las sentencias de los tribunales parecen anteponer la libre competencia centrada en el precio; aunque es posible que simplemente se trate de un retardo en la aplicación de la nueva legislación. En cualquier caso, éste no es un trabajo de derecho, y correspondería a los políticos mejorar la normativa que fuera necesaria para permitir optimizar el retorno social de las licitaciones públicas.

A fin de poder calcular el valor integral se pueden utilizar de forma complementaria diferentes metodologías, algunas ya consolidadas como el análisis DEA, el SROI o el SPOLY, y otras más experimentales como la cuantificación del valor emocional. A largo plazo, consideramos que la opción óptima pasaría por desarrollar una contabilidad social debidamente sistematizada y regulada, que facilitara la visualización real del valor generado o destruido por las diferentes organizaciones en su actividad social o mercantil.

En un plazo más breve, consideramos que las licitaciones deben ampliar su objeto no sólo a la prestación de una determinada obra o servicio, sino a la generación integral de valor en la realización de la citada obra o servicio; desarrollando un análisis sobre el retorno del gasto (SROI) de la licitación. Para dicho análisis debieran tenerse en cuenta cuatro aspectos complementarios: 1) la información sobre la distribución del valor por parte de las organizaciones ofertantes, tanto real como referida al proceso de licitación; 2) la información sobre generación de valor social específico, animando a las organizaciones, especialmente a las sociales, a que realicen el proceso de análisis y cuantificación ${ }^{7}$; 3) una valoración del riesgo potencial atribuido a cada oferta, tanto en relación con la posible merma de calidad como al riesgo de insostenibilidad; y 4) el valor emocional generado en el conjunto de stakeholder, que a falta de una metodología contrastada se podría concretar en el compromiso de alcanzar determinados niveles de satisfacción emocional por parte de los diferentes grupos de interés.

En relación con las futuras investigaciones, nos parece necesario el desarrollo de dos líneas complementarias; de una parte, el análisis empírico comparado de diferentes licitaciones, contrastando el resultado de la metodología centrada en el precio con la centrada en el valor; de forma que se pudiera visualizar cuantitativamente el valor que se podría generar, o perder, para el conjunto de los ciudadanos, a través de las licitaciones. En segundo lugar, sería necesario el trabajar en una propuesta metodológica concreta que permitiera su utilización práctica, cumpliendo los requisitos de rigurosidad, objetividad y libertad de competencia, en las diferentes licitaciones públicas.

7.- Cuando la DYA perdió la licitación del transporte sanitario urgente en Bizkaia, tanto ellos como una parte importante de la sociedad percibían que generaban un valor social diferencial con la empresa adjudicataria; sin embargo, en varias reuniones mantenidas con los responsables de la entidad, fueron incapaces de concretar ninguna actuación específica generadora de valor social. Posiblemente sólo se debiera a que no habían reflexionado sobre su objetivación, menos aún sobre su cuantificación; pero si los propios responsables no son capaces de identificar y cuantificar el valor social que generan, es imposible que podamos esperar que la administración lo haga por su cuenta y riesgo. 


\section{Referencias}

ADLER, P. \& KWON, S. (2002): "Social capital: prospects for a new concept", The Academy of Management Review, 27 (1), 17-40.

AECA (2000): Indicadores de Gestión para las entidades públicas, documento n ${ }^{0} 16$.

AECA (2002): Indicadores para la gestión Empresarial, Working Paper n 17, AECA Press, Madrid.

APARICIO, A.G. (2013): "El análisis coste-beneficio como herramienta para una gestión pública basada en evidencias", Economía Industrial, 390, 23-32.

ARINDRAJIT, D. \& KEN, J. (2004): Hidden Cost of Wal-Mart Jobs: Use of Safety Net Programs by Wal-Mart Workers in California, Briefing Paper Series, UC Berkeley.

BAJARI, P. \& LEWIS, G. (2011): "Procurement Contracting with Time Incentives: Theory and Evidence", Quarterly Journal of Economics, 126, 1173-1211.

BERGMAN, M.A. \& LUNDBERG, S. (2013): "Tender evaluation and supplier selection methods in public procurement", Journal of Purchasing and Supply Management, 19 (2), 73-83.

CASCIO, W.F. (2006): "Decency means more than 'Always low prices': A comparison of Costco to WalMart's Sam's Club", The Academy of Management Perspectives, 20 (3), 26-37.

CLARK, C., ROSENZWEIG, W., LONG, D. \& OLSEN, S. (2004): Double bottom line project report: Assessing social impact in double bottom line ventures, Columbia Business School.

CNMC (2015): PRO/CNMC/001/15: Análisis de la contratación pública en España: oportunidades de mejora desde el punto de vista de la competencia, www.cnmc.es

CONGRESO DE LOS DIPUTADOS (2013): Proposición de Ley, BOCG serie B, núm. 147-1, de 29/11/2013

EDLER, J. \& GEORGHIOU, L. (2007): "Public procurement and innovation Resurrecting the demand side", Research Policy, 36 (7), 949-963.

EMERSON, J. \& WACHOWITZ, J. \& CHUN, S. (2000): Social return on investment: exploring aspects of value creation in the nonprofit sector, Chapter 8, 131-173. The Robert Enterprise Development Fund. Retrieved November 1, 2013 from http://www.redf.com.

FALAGARIO, M., SCIANCALEPORE, F., COSTANTINO, N. \& PIETROFORTE, R. (2012): "Using a DEA-cross efficiency approach in public procurement tenders", European Journal of Operational Research, 218 (2), 523-529. 
FISHMAN, C. (2006a): "The Wal-Mart effect and a decent society: who knew shopping was so important?", The Academy of Management Perspectives, 20 (3), 6-25.

FISHMAN, C. (2006b): The Wal-Mart effect: how the world's most powerful company really works and how it's transforming the American economy, Penguin.

FONS, D.M. (2009): Cláusulas sociales, libre competencia y contratación pública, Fundación Alternativas.

FONS, D.M. (2015): Las restricciones a las Cláusulas Sociales en la Contratación Publica impuesta por la libre prestación de servicios, Comentario a la STJUE de 18 de Septiembre de 2014, asunto C-549/13.

FREEMAN, R.E. (2006): "The Wal-Mart effect and business, ethics, and society", Academy of Management Perspectives, 20 (3), 38-40.

FRITH, L. (2014): "Social enterprises, health-care provision and ethical capital", Social Enterprise Journal, 10 (2), 105-120.

GALLARDO, J.M.C. (2014): "Las nuevas Directivas europeas sobre contratación pública: claves para una primera lectura", Contratación administrativa práctica: Revista de la contratación administrativa y de los contratistas, 131, 69-73.

GARCIA, J.M. \& BAKAIKOA, B.B. (2014): "El papel de la Economía Social en la contratación pública del Gobierno vasco entre 2010 y 2012", CIRIEC-España, Revista de Economía Pública, Social y Cooperativa, 82, 207-232.

GELDERMAN, C.J., GHIJSEN, P.W.T. \& BRUGMAN, M.J. (2006): "Public procurement and EU tendering directives-explaining non-compliance", International Journal of Public Sector Management, 19 (7), $702-714$.

GLOBAL REPORTING INICIATIVE [GRI] (2013): Sustainability Reporting Guidelines 4, Reporting Principles and standar Disclosures.

GOETSCH, D.L. \& DAVIS, S.B. (2014): Quality management for organizational excellence, Pearson: London.

GONZÁLEZ DE OLANO, G. \& NAVARRO, J.A. (2014): "Comentarios a la Directiva 2014/23/UE del parlamento Europeo y del Consejo del Consejo, de 26 de Febrero de 2014, relativa a la adjudicación de contratos de concesión", Actualidad Jurídica Uría Menéndez, 37-2014.

GONZÁLEZ, J.P., ANDRIOLI, D. \& SILVA, N. (2013): Cuarto estado financiero sintético y su uso como estado proyectado en la evaluación social de las decisiones de inversión, XXX Conferencia Interamericana de Contabilidad, Trabajo Nacional, Uruguay.

GUASCH, S. (2015): Contabilidad simultánea: Valoración y control de los intangibles en la gestión integral, ACCID, Barcelona. 
HINOJOZA, D.M. \& FALCÓN, E.P. (2005): "Flujo de caja y tasa de corte para la evaluación de proyectos de inversión", Industrial Data, 8 (2), 23-27.

HOMMEN, L. \& ROLFSTAM, M. (2009): "Public procurement and innovation: towards a taxonomy", Journal of Public Procurement, 9 (1), 17-35.

KANAPINSKAS, V., PLYTNIKAS, Ž, \& TVARONAVI IEN, A. (2014): "Sustainable Public Procurement: Realization of the Social Aspect in Republic of Lithuania", Verslas: teorija ir praktika, 1 (4), 302315.

LANG, L., POULSEN, A. \& STULZ, R. (1995): "Asset sales, firm performance, and the agency costs of managerial discretion", Journal of Financial Economics, 37 (1), 3-37.

LEWIS, B.R. \& GABRIELSEN, G.O. (1998): "Intra-organisational aspects of service quality management: the employees' perspective", Service Industries Journal, 18 (2), 64-89.

LORENTZIADIS, P.L. (2010): "Post-objective determination of weights of the evaluation factors in public procurement tenders", European journal of operational research, 200 (1), 261-267.

MCCRUDDEN, C. (2004): "Using public procurement to achieve social outcomes", Natural resources Forum, 28 (4), 257-267.

MIGUÉ, J.L., BELANGER, G. \& NISKANEN, W.A. (1974): "Toward a general theory of managerial discretion", Public choice, 17 (1), 27-47.

MILGROM, P. (2004): Putting Auction Theory to Work, Cambridge University Press, Cambridge, UK.

MILLER, G. (2004): The Hidden Price We All Pay for Wal-Mart, A Report by the Democratic Staff of the Committee on Education and the Workforce U.S. House of the Representatives.

MULGAN, G. (2010): "Measuring Social Value", Stanford Social Innovation Review, 8 (3), 38-43.

OLSEN, S. \& GALIMIDI, B. (2008): Catalog of approaches to Impact Measurement: Assessing Social Impact in Private Ventures, The Rockefeller Foundation.

OLSEN, S. \& NICHOLLS, J. (2005): A Framework for Approaches to SROI, Draft for Haas Social Metrics Conference Reviewers (Working Paper).

PERERA ALDAMA, L. \& ZICARI, A. (2012): "Value-added reporting as a tool for sustainability: a Latin American experience. Corporate Governance", The international journal of business in society, 12 , (4), 485-498.

PERMAN, R. (2003): Natural resource and environmental economics, Pearson Education.

RETOLAZA, J.L. \& SAN-JOSE, L. (2011): "Social economy and stakeholder theory, an integrative framework for socialization of the capitalism", CIRIEC-España, Revista de Economía Pública, Social y Cooperativa, 73, 193-213. 
RETOLAZA, J.L., RUIZ-ROQUEÑI, M., ARAUJO, A. \& MUGARRA, A. (2008): "Eficiencia en las empresas de inserción y apoyo público", Zerbitzuan: Gizarte zerbitzuetarako aldizkaria. Revista de servicios sociales, 44, 39-54.

RETOLAZA, J.L., SAN-JOSE, L. \& RUIZ-ROQUEÑI, M. (2014a): "Ontological Stakeholder View: An Innovative Proposition", Global Business Review, 15 (1), 25-36.

RETOLAZA, J.L., RUIZ-ROQUEÑl, M., SAN-JOSE, L. \& BARRUTIA, J. (2014b): "Cuantificación del valor social: propuesta metodológica y aplicación al caso de Lantegi Batuak", Zerbitzuan: Gizarte zerbitzuetarako aldizkaria. Revista de servicios sociales, 55, 17-33.

RETOLAZA, J.L., SAN-JOSE, L. \& RUIZ-ROQUEÑI, M. (2015a): "Monetarizing the social value: theory and evidence", CIRIEC-España, Revista de Economía Pública, Social y Cooperativa, 83, 4362.

RETOLAZA, J.L., SÁNCHEZ, P., TARIFA, P., RUIZ-ROQUEÑI, M., SAN-JOSE, L. \& AYUSO, L. (2015b): Análisis del valor social de la Fundación Formació i Treball: Una aproximación monetaria al cálculo del valor social, Cátedra Mango, Documento de trabajo n²2, Barcelona.

RETOLAZA, J.L., SAN-JOSE, L. \& RUIZ-ROQUEÑI, M. (2016): Social Accounting for Sustainability: Monetizing the Social Value, Berlin Heidelberg: Springer.

RUIZ-ROQUEÑI, M. \& RETOLAZA, J.L. (2005): "La auditoría social como instrumento de posicionamiento de la economía solidaria", CIRIEC-España, Revista de Economía Pública, Social y Cooperativa, 53, 285-304.

RUIZ-ROQUEÑI, M., RETOLAZA, J.L. \& MUGARRA, A. (2007): "Cláusulas sociales y mercados tutelados: herramientas para la competitividad de las empresas de inserción", CIRIEC-España, Revista de Economía Pública, Social y Cooperativa, 59, 123-151.

SHAPIRO, N. (2004): Company for the people. Seattle Weekly, Revisado el 15 de diciembre de 2015 en: from www.seattleweekly.com/generic/show_print.php.

SMITH, J.B. \& COLGATE, M. (2007): "Customer value creation: a practical framework", Journal of marketing Theory and Practice, 15 (1), 7-23.

SOCIAL VALUE ACT (2013): https://www.gov.uk/government/publications/social-value-act-informationand-resources/social-value-act-information-and-resources

SOCIAL VALUE ACT REVIEW REPORT (2015): https://www.gov.uk/government/consultation s/socialvalue-act-review

STULZ, R. (1990): "Managerial discretion and optimal financing policies", Journal of financial Economics, 26 (1), 3-27.

SWEENEY, J.C. \& SOUTAR, G.N. (2001): "Consumer perceived value: The development of a multiple item scale", Journal of Retailing, 77 (2), 203-220. 
U.E. (2004): Directiva 2004/18/CE del Parlamento Europeo y del Consejo, de 31 de marzo de 2004, sobre coordinación de los procedimientos de adjudicación de los contratos públicos de obras, de suministro y de servicios. Diario Oficial de la Unión Europea de 30 de abril de 2004, $n^{\circ} 134,114$ 240.

U.E. (2006): 08/2006, Guidance on the methodology for carrying out cost-benefit analysis, Working Document No. 4, European Commission Directorate-general Regional Policy, Thematic development, impact, evaluation and innovative actions Evaluation and additionality.

U.E. (2014): Directiva 2014/24/UE del Parlamento europeo y del Consejo de 26 de febrero de 2014 sobre contratación pública y por la que se deroga la Directiva 2004/18/CE, Diario Oficial de la Unión Europea de 28 de Marzo de 2014, 65-241.

U.E. (2015): La evaluación del impacto y la eficacia de la legislación de la U.E. sobre contratación pública.

UYARRA, E. \& FLANAGAN, K. (2010): "Understanding the innovation impacts of public procurement", European Planning Studies, 18 (1), 123-143.

WAGNER-TSUKAMOTO, S. (2007): "Moral agency, profits and the firm: economic revisions to the Friedman Theorem", Journal of Business Ethics, 70 (2), 209-220.

WALKER, H. \& BRAMMER, S. (2009): "Sustainable procurement in the United Kingdom public sector. Supply Chain Management", An International Journal, 14 (2), 128-137.

WANGROW, D.B., SCHEPKER, D.J. \& BARKER, V.L. (2015): "Managerial Discretion An Empirical Review and Focus on Future Research Directions", Journal of Management, 41, 99-135.

ZELLWEGER, T.M. \& ASTRACHAN, J.H. (2008): "On the emotional value of owning a firm", Family Business Review, 21 (4), 347-363.

ZERBE, R.O. \& BELLAS, A.S. (2006): A primer for benefit-cost analysis, Edward Elgar Publishing.

ZERBE, R.O., JR. (2001): Economic Efficiency in Law and Economics, Aldershot England: Edward Elgar.

ZERBE, R.O., JR. (2004): "Should moral sentiments be incorporated into benefit-cost analysis? An example of long-term discounting", Policy Sciences, 37 (3/4), 305-318. 